\title{
Readers Typology: Can Poor Readers Advance to Good Readers?
}

\author{
Sevim Kutlutürk ${ }^{1}$
}

Inonu University School of Foreign Languages, Malatya, Turkey

\begin{abstract}
This study aims to determine the reader's typology among the preparatory class students regarding their use of reading strategies while they read texts written in English, and to find out whether cognitive and metacognitive strategy training can make students advance from poor readers to good readers. The participants of the study were 27 evening education students with the age range between 18 and 22 at the preparatory school of Inonu University School of Foreign Languages in Malatya, Turkey. The students were instructed cognitive and metacognitive reading strategies with the purpose of the study for eight weeks. The study has provided an exciting opportunity to advance both the researcher's and the participants' knowledge of cognitive and metacognitive reading strategies. Throughout the study, the researcher, as the instructor of the participating group, and the students have improved their understanding of reading comprehension of an English written text. Qualitative method was used to collect data. Qualitative data collection instruments involving Think-Aloud Protocol (TAP), learner and researcher's diaries were descriptively analyzed. Findings revealed that the participants raised their awareness on strategy use after involvement in cognitive and metacognitive strategy training. The findings from TAPs also indicated that poor readers could advance to good readers by taking part in the lessons so that weaker students were able to indicate the problems they had encountered, and stronger ones could reveal what made them successful.
\end{abstract}

\section{Suggested Citation:}

Kutlutürk, S. (2020). Readers Typology: Can Poor Readers Advance to Good Readers? International Journal of Academic Research in Education, 6(1), 46-55. DOI: 10.17985/ijare.800247

\footnotetext{
${ }^{1}$ İnönü University, School of Foreign Languages, sevim.kutluturk@inonu.edu.tr
} 


\section{INTRODUCTION}

Reading is an integrative skill in learning English along with writing, speaking and listening. As a result of changes in understanding of language, however, there has been an increasing concern over teaching cognitive and metacognitive reading strategies. Learners need to be taught how to read and develop their reading abilities through some reading materials using the appropriate strategies. Keene \& Zimmermann (2013) state "the beauty of the comprehension strategies is that they give teachers a way to make explicit and visible the thinking that goes on in the minds of good readers" (p. 605). What makes a good reader different from a poor reader is the fact that good readers are the fluent readers, and they can spontaneously use a number of strategies to understand what they read. Good readers and poor readers use different reading strategies when they comprehend a text (Spring, 1985). A good reader makes use of various strategies to comprehend a text during reading comprehension process (Brown et al. 1982). He or she receives new information through the text and integrates it with his or her own previous knowledge.

A good reader does not mean highly skilled at his or her reading speed. A high-speed reader can only be a good one if he or she is able to utilize the key words to understand a sentence without having completely read it in a quick manner. McLaughlin (1969) claimed to have a high-speed reader in his study group, but did not claim that the reader was more skilful than the others in comprehending the text (as cited in Carver, 1985). Carver also mentioned that the speed-reading group in his study did not summarize the text better than the slower ones (Carver, 1985). Cubukcu (2008) points out that the poor readers are unable to use the right strategies where required, and are unable to monitor their reading comprehension process. In a study which set out to determine good and poor readers' awareness, Garner (1980) found "good readers noticed the disruptive effect of the altered material and poor readers did not" (p. 55). Grenfell \& Harris (1999) suggest that poor readers should be given the reasons for their comprehension failure because they are deficient in their strategy use. Similarly, Rubin (1975) claims that poor readers are not aware of interchangeable usage of the strategies. On the other hand, McDonough, Shaw \& Masuhara (2013) assert, a good reader can identify his or her strategy according to the purpose of the text to be read. If the purpose of reading is to get an overall idea, there is no need for reading the text in detail. On the contrary, if the instructional goal of the reading activity is to learn vocabulary and structure, it is necessary to read the text in detail.

\section{Review of Related Literature}

\section{Language Learners}

Rubin (1975) stated that all individuals were capable of easily learning the language used in the community they were born. She also pointed out that some language learners were good at second language learning, but some of them were poor. Rubin suggested identifying the strategies which were followed by those successful learners, and teach them to poor ones. She defined the good learners as successful guessers, inference makers, and clues users. According to Rubin, good language learning depends on three variables: "aptitude, motivation, and opportunity" (1975, p.42). As cited in Ellis (2015), "Carroll saw language aptitude" is determined by the time taken by a student to learn a given task (p. 39). According to Ellis (1985), "aptitude refers to the special ability a learner has for learning a second language" (p.293). Krashen (2000) also claimed that some learners had the special aptitude to understand the target language. Rubin pointed out that the second variable which good language learning depended on was motivation (1975). As teachers, we need to demand the use of the language in the classroom as reading alone does not suffice. Macnamara (1971) acknowledged the deficiency of motivation in the classroom for language learning and added that the streets were better places for language learners. In contrast to Macnamara, Rubin (1975) argues that good language learners are motivated to use the target language, no matter where they are. Likewise, Ellis (2015) holds the view "a learner's motivation is 
influenced by other learners; the dynamics of classroom or of a learning group affect the extent to which individual learners are motivated, both overall and when performing specific tasks" (p. 55). The third variable, opportunity, enables the language learners to practice what they have learned. As Rubin noted that good language learners will create opportunities to use the language which they have learnt, where poor learners will merely passively conduct what has been assigned (1975). Grenfell \& Harris (1999) pointed out "if we can find out what good language learners do, then maybe we can tell the other learners in order to improve their chances (p. 46). Huang (2006) explains that learners may be in a position to read for various reasons, but they have similar needs that should be fulfilled for them to provide the learning effort, that is reading. As teachers, we should train the language learners to use their competences in order to interpret the text they read. When the students acquire the strategies they are instructed, they will be fluent readers. Fluent readers do not need to make a plan, but can make immediate decisions and interchangeably, whenever necessary, use different strategies.

\section{Language Learning Strategies}

Language learning strategies help learners to organize and manage the ways in which they learn and, therefore, reach a proficient level in reading (O'Malley \& Chamot, 1990; Oxford, 1990; Cohen, 1995). Macnamara (1971) explained language learning process at different stages;

... babies pick up their mother tongue with what seems like great ease, and young children in suitable environments pick up a second language with little trouble, whereas adults seem to struggle ineffectively with a new language and impose the phonology and the syntax of their mother tongue on the new language (p.480).

O'Malley \& Chamot (1990) set apart the learning strategies into three distinct groups: cognitive strategies, which are more involved with individual learning tasks, and social/affective strategies, which are concerned with the influence of social and affected process on learning, and "metacognitive strategies involve thinking about the learning processes, planning for learning, monitoring of comprehension or production while it is taking place" and they also add, subsequently, there is selfevaluation which takes place after the task has been completed (O'Malley \& Chamot, 1990, p. 8). According to Oxford, relevant learning strategies focus on attaining communicative competence amongst learners. She mentions that this can be done in either general or specific ways and done in order to encourage the development of communicative competence. The aim of these strategies is to help learners to participate actively in authentic communication, by using meaningful and contextualized language to create realistic interaction amongst learners (Oxford, 1990). She also reports that cognitive strategies are the mostly applied strategies by the language learners, and a combination of four strategies, namely, practicing, receiving and sending messages, analyzing and reasoning, and creating a structure for input and output. Among them, 'practicing strategies' are the most important ones to make the students foster the formulas and patterns of the language through many repetitions. 'Receiving and sending messages' strategies such as skimming and scanning strategies are used to grasp the main idea quickly, or lift the specific information from a text. 'Analyzing and reasoning strategies' are those that learners use to create a mental bridge between incoming information and the previous knowledge in their mind. The last group of strategies Oxford highlights is creating a structure for input and output strategies which are used for underlining the focused information, taking notes, or summarizing the paragraph to comprehend (Oxford, 1990). Gagne \& White (1978) claimed if the images were added during the process of comprehension, the verbal items would be easily stored. According to them, using imagery creates mental links with images to help the learner remember information. 


\section{Process of Reading Comprehension}

Reading comprehension is a process which simultaneously extracts and constructs the meaning of a text. Comprehension can be divided into three parts as the reader who does the comprehending, the text that is being comprehended, and the activity that is part of the comprehension (Schoenbach, Greenleaf \& Murphy, 2012). For a reader to be successful at comprehension, he or she must possess cognitive capacities, the necessary motivation, and sufficient knowledge, for example, of the overall topic of the text. Texts can be difficult or easy, depending largely on the relationship between the content of the text and the abilities and knowledge of the reader. Other contributing factors leading to the successful comprehension of a text are the type of activity which is applicable to that text and appropriate and adequate instruction.

\section{Purpose of the study}

This study aimed to address the following research questions:

1. Are the students good or poor readers of the text written in English regarding their use of reading strategies?

2. Is it possible to advance poor readers to good readers through involvement in cognitive and metacognitive reading strategy training in English classes?

\section{METHOD}

In this study, both cognitive and metacognitive reading strategies were instructed for eight weeks to enhance students' learning experiences using qualitative method instruments such as diaries and thinkaloud protocol (TAP).

\section{The Context of the Study and the Participants}

This study was conducted in the context of teaching English as a foreign language to preparatory class students at Inonu University, in 2015-2016 academic year. The participants of the study were 27 evening education students with the age between 18 and 22. Among 27 students, 14 of them were male and 13 of them were female. All the students' mother tongue was Turkish. In order to determine their language proficiency level, the participants were given a placement test at the beginning of the educational year. Therefore, all the students placed in the group were at the same level, beginner.

\section{Research Design}

Qualitative method was used in the study. The case was studied using the natural process in a natural setting. The qualitative method relies on the interpretations of data as gathered from observations, interviews and diaries. As taking the advantage of qualitative research method, the order of data collection phases could be changed for the benefit of the study. As Merriam (2002) claims data collecting and data analyzing processes concurrently take place in qualitative research. In other words, a researcher does not need to wait for data collection to be completed for data analysis. 


\section{Instruments}

\section{Researcher and Learners Diaries}

As Bailey (1991) noted both teachers and learners could make use of diaries to keep their experiences, perceptions, and observations. Data gathered from diaries provides deep understanding to the researcher about the learning process. Keeping a diary on a weekly basis enabled awareness to the researcher about the learning process in the classroom, and did not allow overlooking any worthy information that might be crucial for the study (Bailey, 1991).

Learners' diaries are forms of self-report that make students record their reflections on learning process (Oxford, 1990). The participants were asked to monitor and evaluate their process of strategy use while keeping a diary. They were also asked to record whether they were capable of transitioning from one strategy to other when there was a need, furthermore, which strategy they mostly used, and which one better worked.

\section{Think-Aloud Protocol}

In this present study, think-aloud protocol (TAP) was conducted to gather verbal data from the participants while they were on task in the fourth week. As O'Malley \& Chamot (1990) suggested, a thinkaloud protocol was conducted in participants' native language based on the fact that learners can better express their feelings and considerations in their native language. TAP was carried out in the classroom setting to make the students involved in the activity and explore their strategy use, perceptions and feelings about the task on hand. The reading text used for TAP was about Galileo Galilei-the father of modern science, and it was obtained from New Headway Elementary Workbook (Fourth Edition) by Liz and John Soars (2011). Through think-aloud protocol, having reflected their cognitive processes, participants said whatever came to their mind as responding to the questions that were related to the task on hand. Think-aloud strategy enriched the verbal data collected in the natural setting for the study.

\section{Data Analysis}

Qualitative data from think-aloud protocol, researcher, and learners' diaries were descriptively analyzed. The perceptions and feelings of the researcher about readers typology and their improvement on strategy use were recorded in the researcher's diary at the end of each week's instruction. The thinkaloud protocol data and learners' diaries data were coded, and necessary ones were analyzed. The data from learners' diaries were translated into English at the analysis stage by the researcher.

\section{FINDINGS}

Having analysed the data from the researcher's diary to find out the answer to the first research question, it was realized that there were some poor readers among the participants who were not aware of the reading strategies such as skimming, scanning, making use of visuals, using context clues and activating background knowledge to comprehend a text written in English (Kutluturk, 2016). Here is the impression of Week 1 implementation from researcher's diary:

"My adult learners claimed they were aware of some reading strategies. They must have been instructed some strategies at preparatory schools for University Entrance Exam (UEE) they took 
to study at universities. However, I realized that some of them were not capable of integrating the strategies they already knew in their native language into English. They were happy when I informed them about the strategy training they were going to be exposed (November 30, 2015)."

As can be understood from the following data, all the participants became aware of the strategies they were instructed. Therefore, the learners became able to use various strategies to comprehend a text in English, and this advanced the poor readers to good ones.

P5DSN: I liked these strategies. From now on, I will use them for all reading tasks. It was easier, faster, and more enjoyable than the other strategies for me to understand the text. I am sure I will not forget the images I created in my mind, so the related information in the text (March 7, 2016).

P5SRK: I think visualizing strategy works well for me to get an idea of the text before reading it. Also, I could use my background knowledge about tattoos, and it helped me to understand the text. I will always use this strategy when I read a text in English.

As Gagne \& White (1978) asserted creating mental imaginary strategies helps to increase the retention of the information for learners. P5DSN claimed that creating mental imaginary strategies helped her to understand the information in the text. P5SRK showed the use of visuals to activate his schema. Learners activate their schema by utilizing their cultural background knowledge to comprehend a written text (Snow, 2002).

P5EBR: ... mmm, I will study vocabulary to improve my reading skill, because I have difficulties with unknown words. My goal is to be a good reader. As you know, my department requires me to be a good reader in English. Most of the sources about philosophy are in English, and I would like to be skilled on reading those materials.

The aim of Think-aloud Protocol was to gather verbal data from the participants so as to explore whether the instruction helped achieve the goal of the study or not. Anderson (1991) pointed out, "A verbal report or think aloud protocol is produced when a reader verbalizes his or her thought processes while completing a given task" (as cited in Yayli, 2010, p.236). From this point of view, in the fourth week of the strategy training program the participants, having reflected their cognitive processes, said whatever came to their mind as responding to the questions that were related to the text on hand.

The text was about Galileo Galilei-the father of modern science by Soars \& Soars (2011). First, the participants were asked to read the text silently and answer the comprehension questions on their own, and then, they read loud and verbalized their cognitive processes as responding to the instructor's questions. The process was conducted as a whole class activity. The researcher asked them if the picture at the bottom was a reminder to them about his inventions. They answered that they recognized him from the picture at the right top of the page and remembered his discoveries from the picture at the left bottom of the page. Although they were slightly instructed about using visuals with the skimming strategy until then, most of the participants were successful at the use of the strategy as it was the fourth week of the strategy instruction. The next question the researcher asked was their initial thought about the text given, and good readers explained:

P4FR: umm... there were some comprehension questions to be answered, and so I firstly read the questions. Then, I read the text. 
P4RD: I remember him from physics classes at secondary school, and thought that the text was about his life and inventions.

P4ZN: mm... I skim and scan the text, and realized from sub-headings that it was about Galileo's life and inventions.

The researcher aimed to implicitly activate the participants' background knowledge, and make them use visuals by choosing such a text. Most of the participants said they firstly skimmed and scanned the text to comprehend, but only P4FR claimed that he read the questions as the first activity. As P4RD, some students used their background knowledge.

The participants were also asked what kind of problems they encountered while reading the text, and how they could cope with those problems. The students had the opportunity to monitor their cognitive processes, and interact with each other using think-aloud strategy. They reported the problems they encountered as in the following:

P4LP: Luckily, I didn't have problems with grammar. I know Galileo was a scientist from the history, and the tense is in simple past. It is easy, but I had difficulties with unknown words. I couldn't guess the meaning of 'prison'.

P4ER: mm... I had difficulties with unknown words, even the word 'prison', but the film I watched last week, 'Prison Break', made me guess the meaning of the word.

From the verbal data, it was obvious that good students were aware of using various strategies as a result of eight-week strategy training, and the interaction among the students gave them the opportunity to be aware of their strengths and weaknesses. Good readers reported the use of some cognitive strategies such as skimming, scanning, making use of visuals, using context clues and activating background knowledge to comprehend the task. Poor readers reported the problems they encountered.

P4FR: I couldn't guess the meaning of 'blind' before, but as following the strategy my friend used, I remembered from the history of astronomy that Galilei was blind in his last years, so I guessed the meaning.

P4HM: mm... I could answer the question of where Galilei was from by scanning the names of the places.

As the participants were monitoring their cognitive processes, they verbalized that they benefited the words with capital letters, numbers, proper nouns, and the names of the places to answer reading comprehension questions related to the text.

Having analyzed the data from the learners' diaries, the researcher also realized that the participants' goals were to become skilful readers and speakers in English. Since all but one of the participants were compulsory prep school students in English, and they would confront materials in English in their educational life at the university and their professional life in the future, they aimed to be good second language speakers and readers using the reading strategies. They were also aware of their weaknesses, and determined the objectives to study vocabulary and grammar. 


\section{DISCUSSION}

In order to discuss the answer to the first research question to determine the reader's typology at their current level, it was recorded in researcher's diary that although the students were mostly proficient readers of the texts written in their mother tongue, and were able to apply relevant reading strategies to them, they were not necessarily able to apply those strategies to the texts written in English. As Zhang (2018) claims learners' strategy use determines their language performance. Garner \& Alexander (1989) claimed "younger and poorer readers, often rely on a single criterion for textual understanding" (p.145). From this point of view, as the students aged between 18 and 22, they were experienced in their perceptions. As Pearson (2008) noted that "today's new knowledge is tomorrow's background knowledge", the young adult learners of the present study were well off with respect to their life experience to make use of their world knowledge (as cited in Harvey \& Goudvis, 2013, p. 437). Another possible explanation for this result might be that the participants were from the departments of Social Sciences at university and had taken instruction on some strategies during preparatory courses for the University Entrance Examination (UEE).

Regarding the second research question, data from think-aloud protocol, researcher's diary, and learners' diaries showed that poor readers could advance to good ones after being involved in cognitive and metacognitive reading strategy training. Therefore, think-aloud strategy allowed the students from all proficiency levels to take part in the lessons so that weaker students were able to indicate the problems they had encountered, and stronger ones could reveal what made them successful (Chamot, 1999). Interaction among the participants gave them the opportunity to be aware of their strengths and weaknesses so that poor readers could follow the good readers.

\section{CONCLUSION}

As Weinstein \& Mayer (1983) explained 'good teaching' is making the students be aware of the way to learn, remember, think and motivate themselves, and according to them, teachers should have the intention to teach the students what to learn and how to learn. Throughout the study, good readers made use of various strategies to comprehend a text during the reading comprehension process. They received new information through the text and integrated it with their own previous knowledge. In Kendeou, Smith \& O'Brien terms, successful reading comprehension "requires the continual integration of incoming information into evolving discourse representation in reader's memory" (2012, p.854). This study has revealed that having explicit metacognitive strategy training made the participants apply different types of strategies to various kinds of texts, and as a result of learning to regulate their thinking, they advanced from poor readers to good readers (Kutluturk \& Yumru, 2017). 


\section{References}

Bailey, K. M. (1991). Diary Studies of Classroom Language Learning: The Doubting Game and the believing Game. Retrieved from http://eric.ed.gov/?q=kathleen+bailey\&ft=on\&id=ED367166

Brown, A. L., Bransford J. D., Ferrara R. A., \& Campione J. C. (1982). Learning, Remembering, and Understanding. Technical Report No. 244.

Carver, R. P. (1985). How Good Are Some of the World's Best Readers?. Reading Research Quarterly, 20 (4), 389-419. doi.org/10.2307/747851.

Chamot, A. U. (1999). The learning strategies handbook. White Plains, NY: Longman.

Cohen, A. D. (1995). Second language learning and use strategies: Clarifying the Issues. Research Report. Revised Version. Minnesota.

Ellis, R. (1985). Understanding second language acquisition. Oxford; New York: Oxford University Press.

Ellis, R. (2015). Understanding Second Language Acquisition. Oxford. Oxford University Press.

Garner, R. (1980). Monitoring of understanding: An investigation of good and poor readers' Awareness of induced miscomprehension of text. Journal of Literacy Research, 12 (1), 55-63.

Garner, R. \& Alexander, P. (1989). Metacognition: Answered and Unanswered Questions. Educational Psychologist, 24 (2), 143-158. doi:10.1207/s15326985ep2402_2.

Grenfell, M., \& Harris, V. (1999). Modern Languages and learning strategies: In Theory and Practice. London: Routledge.

Harvey, S., \& Goudvis, A. (2013). Comprehension at the core. Reading Teacher, 66 (6), 432, 439. doi:10.1002/TRTR.1145.

Huang, S. (2006). Reading English for academic purposes - What situational factors may motivate learners to read? System, 34 (3), 371-383. doi:10.1016/j.system.2006.04.006.

Keene, E. O., \& Zimmermann, S. (2013). Years later, comprehension strategies still at work. The Reading Teacher, 66 (8), 601-606.

Kendeou, P., Smith, E. R., \& O’Brien, E. J. (2013). Updating during reading comprehension: Why causality matters. Journal of Experimental Psychology. Learning, Memory, and Cognition, 39 (3), 854-865.

Krashen, S. D., \& Terrell, T. D. (2000). The natural approach: language acquisition in the classroom. England: Longman.

Kutluturk, S. (2016). An Investigation on the Effects of Using Cognitive and Metacognitive Strategies to Enhance University Students' Reading Skills. Unpublished Master's Thesis, Çağ University, Mersin, Turkey.

Kutluturk, S., \& Yumru, H. (2017). Cognitive and metacognitive strategy training to enhance freshmen's reading skills. International Journal of Language and Literature, 5(1), 7-15.

Macnamara, J., (1971). The Cognitive Strategies of Language Learning. In "Conference on Child Language," preprints of papers presented at the Conference, Chicago, Illinois, November 22-24, p471- 484.

McDonough, J., Shaw, C., \& Masuhara, H. (2013). Materials and methods in ELT: A teacher's guide (3rd ed.). West Sussex, UK: Wiley \& Blackwell. 
Merriam, S. B. (2002). Qualitative research in practice: Examples for discussion and analysis. San Francisco, CA: Jossey-Bass.

O’Malley, J. M., \& Chamot, A. U. (1990). Learning strategies in second language acquisition.

Cambridge University Press.

Oxford, R. (1990). Language learning strategies: What every teacher should know. Boston: Heinle \& Heinle.

Rubin, J. (1975). What the "Good Language Learner" Can Teach Us. TESOL Quarterly, 9 (1), 41.

Schoenbach, R., Greenleaf, C., \& Murphy, L. (2012). Reading for understanding: How reading apprenticeship improves disciplinary learning in secondary and college classrooms. John Wiley \& Sons.

Snow, C. E., (2002). Reading for Understanding: Toward an R\&D Program in Reading Comprehension. Santa Monica, CA: RAND Corporation.

Soars, L., \& Soars, J. (2011). New headway elementary, fourth edition materials. UK: Oxford University Press.

Spring, C. (1985). Comprehension and study strategies reported by university freshmen who are good and poor readers. Instructional Science, 14 (2), 157. doi:10.1007/BF00052395.

Weinstein, C. E., \& Mayer, R. E. (1983). The Teaching of Learning Strategies. In Innovation abstracts. 1983. p. n32.

Yaylı, D. (2010). A think-aloud study: Cognitive and metacognitive reading strategies of ELT Department students. Eurasian Journal of Educational Research, 38, 234-251.

Zhang, L. (2018). Metacognitive and cognitive strategy use in reading comprehension. Springer. 